ROCZNIK ADMINISTRACJI PUBLICZNEJ 2017 (3)

ARTYKUŁY Nauka administracji / Administrative science

DOI 10.4467/24497800RAP.17.013.7064

http://www.ejournals.eu/RAP/

ISSN 2449-7800 (online), ISSN 2449-7797 (print), p. 205-235

Wojtek Lamentowicz ${ }^{1}$

\title{
Wicked Problems and Gordian Knots: an Increased Risk of the Tsunami Effect in Modern Governance
}

\section{What is the Tsunami Effect in strategic thinking ${ }^{2}$ ?}

The Tsunami Effect is a novel idea and a new concept but it refers to a very old human experience of inability and helplessness. It is rare but more frequent than Black Swans discovered and described by Nicholas Taleb. The Tsunami Effect emerges when three extreme components are present in a decision making process:

- Total unpredictability of spontaneous and nonlinear dynamics in an environment of the power system. Anything is possible and may happen but we cannot predict it.

- Fully uncontrolled dynamics prevails over any policy of guided changes.

- Decision-making authorities are unable to invent, design and implement relevant strategies of adaptation, regulation and/or innovation that could adequately respond to challenges and threats. The final limit has been reached and the realm of powerlessness has been unfortunately approached. All actors are unable to find a solution, even a clumsy one. The concept of the Tsunami Effect suggested here is inspired by tsunami in nature as it is hardly predictable and we are rather inefficient in all crisis management operations. It can be useful as a warning for all power holders being a reminder that there are limits to human capability of problem solving. We should imagine that Tsunami Effect may happen even when we are unable to predict it. Strategic imagination in policy making should help in thinking about the risk of complete failure in governance.

The causes of the Tsunami Effect are rooted deeply in institutional frameworks of many social worlds (pre-modern, modern and postmodern)

1 Wojtek Lamentowicz, Chair in Theory \& Philosophy of Law Business \& Administration, University in Gdynia.

2 See more on a broader context of strategic thinking in my latest book Strategia państwa: teoria państwa aktywnego wobec zmian spontanicznych, Elipsa, Warszawa 2015. Some ideas are elaborated in-depth and presented as moral realism in the theory of law in my forthcoming book Status prawny i dynamika porzadku prawnego to be published by the University of Lodz in 2017. 
and human cultures, in acceleration of spontaneous changes, in imbalances and contradictions of complex civilisations. Human reason and knowledge seem to be far from models of pure rationality and we are limited by our bounded rationality. The very belief in pure rationality may foster the emergence of the Tsunami Effect. If one believes in her/his rationality and forgets about many institutional, intellectual and emotional constraints one can easily fall victim to the Tsunami Effect.

Authorities try to tackle problems of uncertainty and disorder by designing strategies of guided changes. The chaotic process of spontaneous changes may invade strategy making and distort perceptions and political judgments. When such distortions go very deep, a decision-making body may be captured and imprisoned by spontaneous dynamism of social developments. A general remedy against this risk is twofold: do not expect anything specific but predict all Black Swans you can only imagine. But clever thinking is obviously not enough.

\section{How does the Tsunami Effect emerges in decision making?}

Let us try to imagine a social chain reaction in a setting of vertical and horizontal interdependencies of very complex dynamic systems.

Stage One

Spontaneous dynamics is a natural background to most threats and challenges to contemporary governance. Due to natural spontaneity, many well-known effects such as the Butterfly Effect, Mountain Effect, Cascade Effect, Domino Effect, Network Effect and Complexity Effect may trigger a chain reaction of high-speed non-linear changes which are hardly predictable. In a short period of time, initial conditions may change in a radical manner.

Stage Two

All effects mentioned above reinforce each other and spill over the decision making area. Conflicts between many stakeholders multiply and unwanted consequences sum up to a mess, a variety of a self-generated disorder in which high energies clash in a growing velocity of actions and counter-actions. Many effects create a Vicious Circle of circular causality.

Stage Third

At the top of this Vicious Circle something new may appear - Emergency Effect when a new holistic system cannot be reduced to the sum of its components and it may have some new characteristics that were not visible in its elements. Emergence turns into an emergency and calls for remedies, for reasonable adjustment or regulation by decisions. When actors in authority try to manage the increasing disorder, it proves that no strategy works properly and some of them increase the intensity of the emerging chaos. So, the Tsunami Effect has arrived. 
This chain reaction is facilitated by the high velocity of changes, by nano-objects and spaces on the one hand and by supersonic speed of our technology on the other. Humans go deeper into the matter and much wider to the Space than ever in our history. So oscillations, turbulences, interferences, and vibrations can be more devastating than ever. Big systems disintegrate, reintegrate, explode and implode faster and consume much more energy than in the very recent past. Real and virtual components mix up into a new mess without clear and sharp boundaries. Pictures are more important than content transmitted in pictures. It is possible that software and soft power is more efficient than hardware and hard power ${ }^{3}$. Everything seems to be connected with everything; almost nothing is excluded and protected.

Diagram 1. Emergence of the Tsunami Effect

Initial Conditions $\longrightarrow$ Exponential changes $\longrightarrow$ Higher velocity Complexity Effect Cascade Effect Network Effect

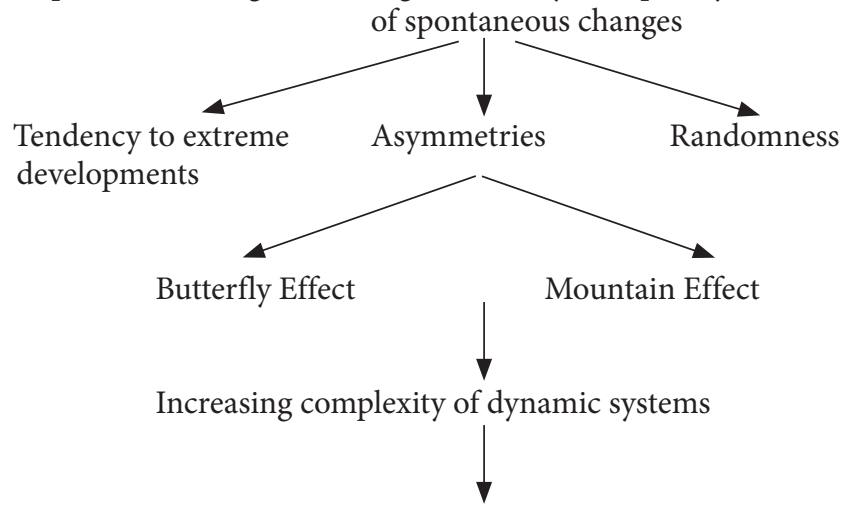

Higher level of chaos in the dynamics of big systems

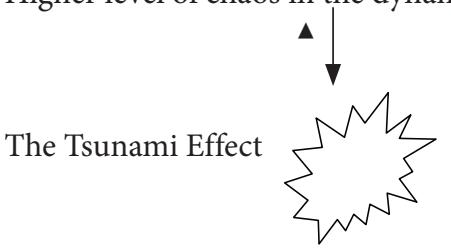

There are many features of the postmodern world which may facilitate the emergence of the Tsunami Effect. In international relations, we see mutual vulnerability of strong and weak states, interdependence, semi-open borders, interference of national and international institutions, disappearance of former distinctions between domestic and foreign policy, tele-presence in real time, compression of time and space, transparency endangered by hidden agendas and secret diplomacy of top leaders.

3 Rethinking Geopolitics, G.O. Tuathail, S. Dalby (eds.), London 1998, p. 27. 
In domestic affairs, cosmopolitan elites manipulate democratic institutions and play with rules of the game which distorts liberal democracy as stipulated by constitutions of nation states. The higher speed and intensity of interactions and acts of communication turns social relations into mere short-lasting contacts. Lonely crowds of precarious social status can hardly be heard by corrupt ruling elites. Low trust in democratic institutions, increasing political cynicism and support for populist parties are a cause for deep concern as the future of liberal democracy seems to be less certain than ever after the Second World War.

In general, we see more non-linear changes, irregular and multidimensional and less predictable and much faster than in the last 50 years, more indeterminacy and randomness, more inequalities in wealth and income distribution, less social mobility, decay of the middle classes, and a "disorder of the risk society" as it was aptly defined by Ulrich Beck.

Linear streams of problems which were usually solved by reforms within strategies of reintegrating evolution are downgraded by the higher visibility of wicked problems and Gordian Knots which brings us to the verge of the Tsunami Effect.

\section{Wicked and super wicked problems: closer to the Tsunami Effect}

First, let us look at some of the things that characterise a tame problem. A tame problem

- has a relatively well-defined and stable problem statement,

- has a definite stopping point, i.e. we know when a solution is reached,

- has a solution which can be objectively evaluated as being right or wrong; belongs to a class of similar problems which can be solved in a similar manner, and has solutions which can be tried and abandoned.

Consequently, tame problems can be solved by bureaucrats or managers if they are properly trained. There can be even algorithms for their solutions which may be elegant and easy to understand for a broader public.

Critical problems threaten the very survival of the system in the short term, decisive action is called for, and people are required to follow the call for action in a highly disciplined way. With this type of problem, a commander takes charge, often using an authoritarian command and control style.

Wicked problems are completely different. Wicked problems are ill-defined, ambiguous and associated with strong moral, political and professional issues. A wicked problem is a problem that is difficult or impossible to solve because of incomplete, contradictory, and changing requirements that are often difficult to recognise. The use of the term "wicked" here has come to denote resistance to resolution because of complex interdependencies rather than moral evil. 


\begin{tabular}{llll} 
& \multicolumn{2}{c}{ FORMS OF } & \multicolumn{2}{c}{ LEITIMATE POWER } \\
& Command & Management & Leadership \\
Space & Tactical & Operational & Strategic \\
Time & Short Term & Medium Term & Long Term \\
Problem & Critical & Tame & Wicked
\end{tabular}

Command: just do it (it does not matter what you think because I can use hard power).

Management: déjà vu (I have seen this problem before. I know what process will solve it. Rational calculation will help).

Leadership: $v u$ jàdé (I have never seen this problem before; I need to get a collective view on what to do about this. Soft power is the best asset in search for clumsy solutions) ${ }^{4}$.

Rittel and Webber's 1973 formulation of wicked problems in social policy planning specified ten characteristics ${ }^{5}$ :

1. There is no definitive formulation of a wicked problem.

2. Wicked problems have no stopping rule.

3. Solutions to wicked problems are not true-or-false, but good or bad.

4. There is no immediate and no ultimate test of a solution to a wicked problem.

5. Every solution to a wicked problem is a "one-shot operation"; because there is no opportunity to learn by trial and error, every attempt counts significantly.

6. Wicked problems do not have an enumerable (or an exhaustively describable) set of potential solutions, nor is there a well-described set of permissible operations that may be incorporated into the plan.

7. Every wicked problem is essentially unique.

8. Every wicked problem can be considered to be a symptom of another problem.

9. The existence of a discrepancy representing a wicked problem can be explained in numerous ways. The choice of explanation determines the nature of the problem's resolution.

10. The social planner has no right to be wrong (i.e., planners are liable for the consequences of the actions they generate).

Conklin later generalized the concept of problem wickedness to areas other than planning and policy. The defining characteristics are $^{6}$ :

4 K. Grint, The Leadership Challenge of Wicked Problems, Warwick Business School, Warwick University, Slides for Henry Stewart Talks.

5 H.W.J. Rittel, M.M. Webber, Dilemmas in a general theory of planning, "Policy Sciences" 1973, No. 4, p. 155-169.

6 J. Conklin, Dialogue mapping: building shared understanding of wicked problems, Chichester, England: Wiley Publishing 2006. 
1. The problem is not understood until after the formulation of a solution. The solution depends on how the problem is framed and vice versa (i.e. the problem definition depends on the solution).

2. Every wicked problem is essentially novel and unique.

3. Wicked problems have no stopping rule. The constraints that the problem is subject to and the resources needed to solve it change over time.

4. Solutions to wicked problems are not right or wrong.

5. Every solution to a wicked problem is a "one shot operation". Wicked problems have no given alternative solutions. The problem is never solved definitively.

6. Stakeholders have radically different world views and different frames for understanding the problem.

The vicious nature of wicked problems was rightly identified more than 30 years ago: "The search for scientific bases for confronting problems of social policy is bound to fail,

Because of the nature of these problems. They are "wicked" problems, whereas science has developed to deal with "tame" problems. Policy problems cannot be definitively described.

Moreover, in a pluralistic society there is nothing like the indisputable public good; there is no objective definition of equity; policies that respond to social problems cannot be meaningfully correct or false; and it makes no sense to talk about "optimal" solutions to social problems unless severe qualifications are imposed first. Even worse, there are no "solutions" in the sense of definitive and objective answers"'.

The most evident, and important, wicked problems are complex, longterm social and organisational:

- How should we fight the "War on Terror or control climate change"?

- How should reform our health services?

- What can be done in order to reduce inequality of opportunity and standard of living?

- How should scientific and technological development be governed?

- What is a good national immigration policy?

- How do we get genuine democracies to emerge from authoritarian regimes?

- How should we deal with crime and violence in our schools?

- How should our organisation develop in the face of an increasingly uncertain future?

In his work on "Wicked Problems and Social Complexity" (2001), Jeff Conklin writes: "there are two common organizational coping mechanisms that are routinely applied to wicked problems: studying the problem, and taming it. While studying a novel and complex problem is natural and important, it is an approach that will run out of gas quickly if the problem

7 H.W.J. Rittel, M.M. Webber, Dilemmas..., Abstract. 
is wicked. Pure study amounts to procrastination, because little can be learned about a wicked problem by objective data gathering and analysis. Wicked problems demand an opportunity-driven approach; they require making decisions, doing experiments, launching pilot programs, testing prototypes, and so on. Study alone leads to more study, and results

In the condition known as "analysis paralysis", a Catch 22 in which we can't take action until we have more information, but we can't get more information until someone takes action. (...) Attempting to tame a wicked problem, while appealing in the short run, fails in the long run. The wicked problem simply reasserts itself, perhaps in a different guise, as if nothing had been done. Or, worse, sometimes the tame solution exacerbates the problem"'.

Wicked problems may have only clumsy solutions which can be provided by leaders and not by bureaucracy that is trained for dealing with tame problems. A clumsy solution means it is never final but can only alleviate the most painful outcomes of a wicked problem. Leaders should arrange for a collective search for new ideas and innovative strategies rather than for ready-for-use remedies. Leaders must be trained in order to be able to design strategies by doing, by continuous efforts, by trial and error, having in mind public good and common interests. Rittel \&Webber provided us with a simple wisdom: "part of the art of dealing with wicked problems is the art of not knowing too early which type of solution to apply". By keeping our minds open to all options, we have a better opportunity to find at least an agreeable clumsy solution.

Kelly Levin, Benjamin Cashore, Graeme Auld and Steven Bernstein introduced the distinction between "wicked problems" and "super wicked problems" in a 2007 conference paper, which was followed by a 2012 journal article in Policy Sciences. In their discussion of global climate change, they define super wicked problems as having the following additional characteristics:

1. Time is running out.

2. No central authority.

3. Those seeking to solve the problem are also causing it.

4. Policies discount the future irrationally.

While the items that define a wicked problem relate to the problem itself, the items that define a super wicked problem relate to the agent trying to solve it. Weaknesses of the decision-making agency can turn a wicked problem into a super wicked problem.

8 J. Conklin, Wicked Problems \& Social Complexity [in:] Dialogue Mapping: Building Shared Understanding of Wicked Problems, Wiley, New York 2005.

9 K. Levin, B. Cashore, S. Bernstein, G. Auld, Overcoming the tragedy of super wicked problems: constraining our future selves to ameliorate global climate change, "Policy Sciences", Vol. 45 (2), 23 May 2012, p. 123-152. 


\section{Gordian Knots and spontaneous dynamics}

Gordian Knots can occur both within the framework of spontaneous changes that are not controlled by any decision making center (or perhaps are beyond the human capacity of control) or within the framework of a guided process of changes which are to a certain extent human made and can be viewed as a by-product of the use of power and management skills. There is a widely shared view that $75 \%$ of guided change programmes fail in their own terms. It shows how hard it is to be efficient in any policy of guided changes (for example reforms through law making).

A spontaneous process must not always be a "spontaneous order" or "organised complexity" as it is assumed by many neoliberal economists. Sometimes, spontaneity is a pretty disorderly patchwork with many crosscutting paths, overlapping modes of action and contradictory trajectories of changes that are mutually reinforcing and pushing to the extremes. I will not assume that spontaneity is a kind of organised whole or a variety of order. Sometimes it can be more like an order and sometimes not. It is an empirical question and must be studied carefully without any prejudice or any assumption imposed by reason that tends to put models before the real facts of life.

The global system consists of a great variety of spaces and realities; some of those are objective and given and many of those are socially constructed or reconstructed after some periods of creative destruction. Reality is a set of meaningful acts and facts based on tacit assumptions about what is real and on sometimes unclear presumptions which give meaning to our thoughts. Some realities are external and "given" by history or/and nature and some are invented/designed by human beings, intentionally negotiated and even shared by many distinctive communities living on Earth. The global system of the Spaceship Earth ${ }^{10}$ and the entire Universe consists probably of both deterministic and non-deterministic subsystems and we have no sufficient knowledge to make a final judgment which of the two prevail and in what conditions ${ }^{11}$. The suspension of judgment that was recommended by Blaise Pascal (who invented the calculus of probability) is in order in all situations when we are far from certainty in a particular field of study.

The first, purely linguistic intuition tells us that "spontaneous" means that something happens and is uncontrolled, unleashed, unchecked, unguided or poorly guided by human decisions. It is something that resembles the elements of nature and that may produce a lot surprises, unexpected and/or undesirable outcomes. Looking at the phenomenon of spontaneous

10 The Spaceship Earth is a metaphor coined some sixty years ago by R. Buckminster Fuller, an optimist visionary thinker, and designer who invented, among other things, his geodesic domes, synergetics and ephemeralisation.

11 Here it is wise to apply the uncertainty principle and to be rather modest than bold in making hypotheses that jump beyond facts that we know about so little. 
dynamics in a more systematic manner, we can suggest that the defining characteristics of spontaneity are the following:

1. Spontaneity is a particular feature of all dynamic systems, both natural and artificial, because most of the processes are not controlled by power centres and many varieties of forces and energies interact in a contradictory manner. Conflict and cooperation of agents are not regulated by a super arbiter with unlimited power of right settlements and rulings. Realities in which spontaneity occurs are complicated, unclear, fluid, and foggy, if we can use a metaphor that comes from the weather forecasts. In the theory of international relations, the absence of a central rule or coordination centre is viewed as a variety of anarchy in the global affairs...

2. Spontaneous dynamism means that changes are normal and that steady or stationary moments are rather exceptional. Change is a norm and a stationary moment is an exception to this norm. Flows are more natural than solid structures and temporary structures prevail over something we might assume would be permanent. It is both information and energy that flows and changes all aspects of life on the globe. Information seems to be more crucial here as it is a our Sixth Sense that allows us to know beyond our five senses, to know what we did not see, hear, touch, smell or taste. Information that goes beyond our senses is the basis of our decisions and for that reason has a direct impact on our capability to make and to implement strategies that can deal with spontaneous changes in our environments. As changes are more frequent than stagnation, there is more room for the recognition of rhythm in strategic thinking as well as in the social construction of culture. The ability to read the rhythms of changes is conducive to smart reactions to spontaneity of developments. Without that ability to reading and monitor the natural rhythms of spontaneous changes, it would be almost impossible to design innovative, regulatory, and adaptive strategies.

3. Spontaneity is a result of non-linear relations to greater extent than it is conditioned by linear causality and therefore can be understood as chaotic and complex ${ }^{12}$. Non-linearity means that there is a structural tendency to asymmetry of causes and outcomes. Small causes are able to produce effects out of proportion (that is usually named the Butterfly Effect $)^{13}$. Effects of this kind may be much larger and travel longer in

12 Complexity must not be conflated with a complicated reality. A complicated reality is just not simple one and complexity is related to the non-linearity of dynamics.

13 Michael Dillon defines the contemporary global system by three features: circulation (interdependence of elements in permanent flow), complexity (non-linear relations produce an overall asymmetry) and contingency (high frequency randomness and chance and the high level of risk in probabilistic relations); M. Dillon, Global security in the $21^{\text {st }}$ Century [in:] The Globalization of Security, Briefing Paper, Chatham House, October 2005, p. 2-3. 
time that we could think as we were looking at their causes. Big causes, however, can produce very little effect as well. I propose to call this case a Mountain Effect that refers to a famous saying about the mountain which gave birth to mice.

4. The growing speed and velocity of changes in all subsystems of the global system is a fundamental cause of the spontaneous nature of changes ${ }^{14}$. The faster the system and/or its environment changes, the more spontaneous the process can be. Time and space are obviously compressed by a high level of speed and velocity that we know since Einstein discovered it and developed as the theory of relativity. One of the first thinkers who recognised the growing impact of speed in our civilisation was Marc Bloch, who did it already in the 1930s. The factor of speed/velocity is not underestimated any longer but only very few thinkers would dare to claim that the entire evolution of life on Earth is based not on the survival of the fittest but rather on the survival of the fastest organisms in nature ${ }^{15}$. My intuitive hypothesis would be that the very basic survival depends more on adaptation capability as it was suggested by Charles Darwin many years ago. However, the expansion of some organisms depends on their capability to move faster than others and this holds not just in physical and natural spaces. The proposed assumption of spontaneity in this study is based on the hypothesis about the survival of the fittest and expansion of the fastest. The spontaneous world is populated by a wealth of new nomadic people of migrating identities. Social contacts are brief and not deeply rooted. In many spaces of human existence, short-lasting and non-binding contacts replace permanent or enduring social bonds rooted in strong mutual commitments. The movement and mobility of people produces a new speed of action in all areas of life. The higher the speed of changes and motions, the shorter the time spans and people's time perspectives. This aspect of spontaneity is a serious challenge to any strategy that is based on the long-term perspective and risky forecasts about the distant future.

5. Spontaneity is a result of the very plurality of forces and energies operating in a particular space of the global system and of differentiated power potentials of actors and factors ${ }^{16}$. Distinctiveness of forces and

14 Velocity is speed with a specific direction and is presented by vectors. Speed has no direction and is presented by scalars in contemporary physics.

15 T. Leary, B.A. Potter, Evolutionary Agents, Ronin Publishing 2004. It is written by Potter after the death of Leary but it develops some of the latter's basic convictions. Paul Virillio put a proper emphasis on the factor of increasing speed in his explanations of cultural dynamics. Compare his inspiring book Speed and Politics (1977, in French) published in many languages including Polish; P. Virillio, Prędkość i polityka, Wydawnictwo Sic!, Warszawa 2008.

16 Power in physics is defined as a ratio of work that can be done in a specific time span. Power equals the ratio of work and time. Both physical and political concepts of power put a stress on capability to get something done in the time-space of reality. This 
energies of actors may be less visible as they can melt into a mass without faces.

6. Spontaneous changes are self-induced and may be driven by self-generating energy coming from the interaction of various social forces that are not clearly visible on the surface of events. Due to these characteristics, spontaneous changes are not easy to study, explain, interpret and predict. This is well known by social psychologists who study the outbreak of hatred and aggression within a lonely crowd or group think effects in deliberating groups of decision makers. It is not the result of a hidden plot of some actors but rather an outcome of an interdependence of forces that are not precisely identified by social sciences.

This self-generated dynamism of spontaneous processes has far reaching consequences for strategic thinking and future forecasting that cannot be elaborated here. One aspect of strategy making is extremely relevant however: prevention is always more demanding and more ambitious than intervention as it presumes high ability to predict and self-generated dynamism is not easy to predict, of course.

Spontaneous dynamism of environments provides an opportunity to any intelligent system of organised power to react to this challenging condition in three distinctive ways - 1 . The system can adapt to spontaneity; 2 . It can regulate spontaneous changes by actively influencing some parameters of changes such as speed, directions, scope or intensity, and 3. It can be innovative by efforts to create something new that was not and probably could not be created by spontaneous dynamism ${ }^{17}$. Adaptation, regulation and innovation are the foundation of a typology that can be applied to global governance systems, international organisations, political systems of countries and smaller regions within nation-states. We can assume that the effect of a specific strategy can be evaluated in these terms as well. Adaptation is the lowest level of ambitions of the power centre that reacts to spontaneity. Adaptation is based on reading strong and weak signals coming from the environment and doing something that is indispensable for the survival of the system under particular conditions. The medium level of ambition would be the regulation that unfortunately is very frequently misguided and sometimes may foster or aggravate Gordian Knots. The most demanding is an innovative strategy (whose effects can be called an innovative function) as it wants to introduce something new to a spontaneous flow of changes around the system and/or in the system itself. Regulatory and innovative effects are the most precious fruit of intelligent human agency in the worlds

pragmatic aspect of power is essential for understanding spontaneous developments both in nature and human culture.

17 This triple function approach was developed by myself in the early 1970s and then applied to the study of functions of the political system and of the State. W. Lamentowicz, Reformizm szwedzki, PWN, Warszawa 1977 and in my book Państwo wspótczesne, wyd. 2, Wydawnictwa Szkolne i Pedagogiczne, Warszawa 1996. 
we live in. Each of the three modes of responses can be applied as a policy of prevention or as a policy of intervention.

Within the spaces of spontaneous changes in the global system, the Gordian Knots appear as a bundle or as a bunch of interlocked and interconnected problems that are results of all characteristic features of spontaneous changes discussed above. A Gordian Knot is not a single problem that can be solved separately as if it was independent from many other problems. We cannot dissolve this bundle of problems just one by one in a piecemeal manner of reform policy or within a framework of business as usual scenario of the future ${ }^{18}$.

The Gordian Knot is a strongly knitted set of long-lasting problems with a wide scope of impacts and a great diversity of impacts that increase threats and risks but if solved by an Alexandrian Solution, those problems may allow for reaching a turning point in a trajectory of spontaneous changes.

The long-lasting nature of the problem that we name a Gordian Knot may be produced in two distinctive ways. First of all, it seems to be a deeply rooted legacy of the past, an outcome of history of long duration that leads to some kind of backwardness, lagging behind or dropping out of the mainstream of changes in a specific time period within the context of a particular civilisation. The second route that leads to a Gordian Knot are delays in providing solutions by power centres or low efficiency in efforts to guide changes. The most important source of cognitive errors here is hidden in the intersection of the remote past and the very fast speed of changes at present that may obliterate the distant future in searching for strategic solutions.

When saying that a Gordian Knot is capable of producing a wide scope of impacts, we mean that it may:

- strongly influence one and single but very large space (for example global economic growth or global security) in the global system or

- significantly influence many different spaces (such as economics, natural environment, or social and cultural) and

- as a result, large numbers of people can be directly or indirectly affected by its occurrence.

The Gordian Knot is a challenge to many layers of power centres as it may produce threats, risks and disasters. There are numerous points of possible intervention as shown in the model of circular causality. What makes a Gordian Knot even worse is lack of unique "correct" view of the problem and its possible consequences. Different views of the problem and conflicting values of stakeholders may produce plenty of contradictory solutions.

18 Russell Ackoff and Robert Horn define "social mess" by stressing that it is a "set of interrelated problems". Not all Gordian Knots in my theory can be perceived as a variety of social mess, however. 
Diagram 2. Structure of the Gordian Knot of mis-development in post colonial societies (circular causality in a vicious circle)

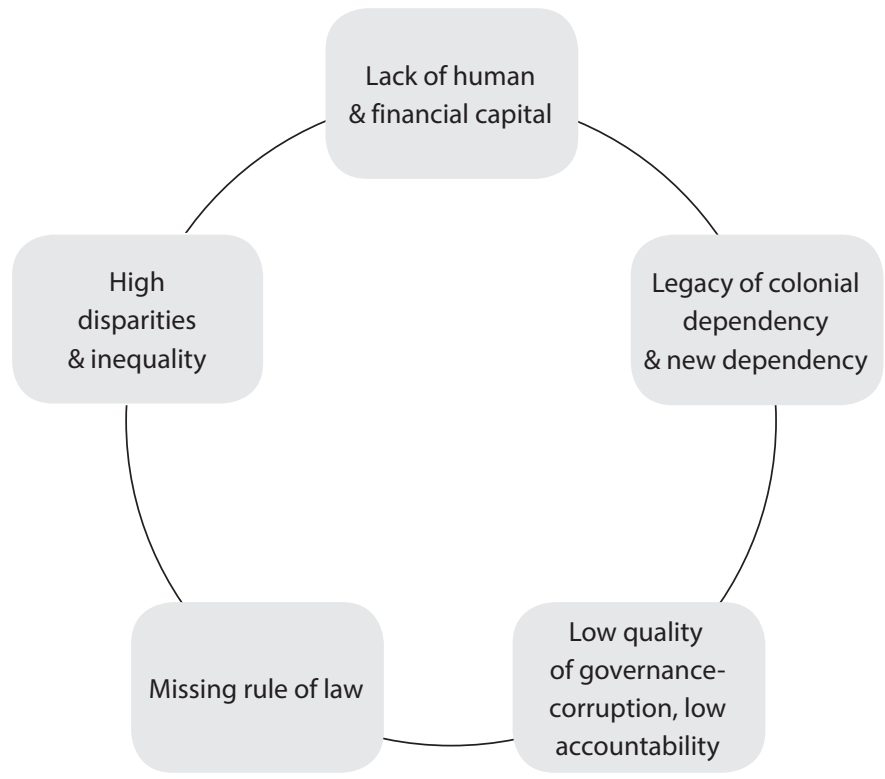

Uncertainty of data and forecasts increases the overall ambiguity. Most designed policies of reform are confronted with a strong resistance to change.

On the other hand, it is an opportunity to find a bold solution and to reach a turning point that may pave the way for a new development and to progress. Our history is perhaps a by-product of lost opportunities on many occasions but to a degree it is also a product of our dreams and visionary actions. Pessimists attach more attention to lost opportunities. Optimists believe that clever adaptation, successful regulation and creative innovation are feasible and can be achieved by a well designed strategy and concerted action.

Gordian Knots may be of high or low acuteness and of high or low predictability. As they are long-lasting problems, they are quite easily predictable and highly visible but sometimes not perceived by power holders as Gordian Knots and are still neglected and postponed. The biggest challenge to our intellectual capacity is the question how to distinguish a Gordian Knot from ordinary bundles of troubles that occur so frequently in the world where we live. The world of high speed can bring any situation to its extremes. This is much visible nowadays and it can be a result of problems that reinforce each other. As in the philosophy of Mani, the distinction between two polarised points of reference may persist without any reasonable hope of finding a synthesis that was posited by the 
old dialectics of Hegel and his idea of Aufhebung ${ }^{19}$. It could be that due to Gordian Knots, the well known binary and contradictory oppositions tend to be more and more polarised and coexist in the long run. Therefore, the poor and rich, weak and strong, slow moving and fast moving, creative and totally uneducated are becoming even more unequal than they used to be some time ago. I propose to call this particular tendency a Polarization Effect $^{20}$. The asymmetric relations and the high speed of interactions are conducive to the emergence and persistence of Gordian Knots.

The asymmetry is manifold and it may be seen almost everywhere: asymmetric are forces and resources, skills and identities, causes and reasons, causes and outcomes, sizes and volumes, spaces and speeds, duration and time horizon of our strategies. As a consequence, the reality of the asymmetrical world is messy, chaotic, and disorganised. What is worse, many asymmetries are multi-layered and cross-cutting as the density of networks increases and new, more sophisticated hierarchies are manufactured (such as the digital divide based on unequal access to broadband Internet) in a supposedly flat and single world of multimedia and telecommunication.

For the general definition of the Gordian Knot, it is essential to understand the difference between the problems generated by hierarchies and asymmetrical relations and problems that emerge from the horizontal networks of fast flows and great number of nods. Both vertical and horizontal structures can be conducive to Gordian Knots but in a different manner. In a hierarchical world, the problem is unresolved for a long time due to the vested interests of the ruling elites. In the horizontal structure of network society, it is easier to identify a Gordian Knot and exert some pressure on decision makers in order to persuade them to search for adequate solutions. In conclusion, we may say that:

1. The aspect of fast speed is more relevant for understanding the mode of behaviour of horizontal networks.

2. The aspect of long duration is more painful in vertical, very slim hierarchies that are still with us in many areas of life in many regions of the globe. Status of persons and institutions is unequal and many statuses are inherited from former generations of the same families.

The question of resistance to change really matters. In a slim hierarchy, resistance may be stronger at the top of it, but in a horizontal community the resistance is more widely distributed and in many cases will be stronger in

19 Jean Baudrillard rightly distinguished between the Manichean duality that leans to the extremes and the dialectics of thesis-antithesis that may eventually dissolve into a new synthesis that can restore a better harmony after a long period of contradictions.

20 Nassim N. Taleb invented an inspiring binary model of Extremistan and Mediocristan and elaborated it in his book entitled Fooled by Randomness: The Hidden Role of Chance in Life and in the Markets, Penguin Books, London 2004 and The Black Swan: The Impact of the Highly Improbable, Penguin Books, London 2007. 
the lower strata of the community. Associative and hierarchical relationships of parts of intelligent systems were distinguished by Ben Goertzel and successfully used in many of his studies on cognition and mathematical modeling ${ }^{21}$. Associative relationships can be represented as an " $\mathrm{A}$ and $\mathrm{B}$ have often occurred together" and we can study it by statistical correlations. More relevant are hierarchical relationships that are represented in the following forms: A is a special case of B, A precedes B, A is a part of B, A is higher positioned than $\mathrm{B}$, and $\mathrm{A}$ occupies a larger space than $\mathrm{B}^{22}$.

Our hypothesis is that Gordian Knots are to a greater extent produced and reproduced in the long run by tensions and contradictions arising from multiple hierarchical relationships than by associative relationships. On the other hand, however, very long or almost permanent joint presence of two or more objects (i.e. institutions, norms, values, traditions, religious beliefs, habits, etc.) may suggest that it is not a coincidence and that a long-lasting set of problems can be explained by this permanent interwoven set of facts. Anyhow, the interplay of associative and hierarchical relationships is a proper focus for the study of Gordian Knots in a specific time frame and space.

Identities of actors (inherited, ascribed to them and freely constructed) are very important for the identification of Gordian Knots. Who are the principal players in a specific arena, how they define themselves, where they locate game-changers and pace-setters in a specific space under study - this is a set a fundamental questions for a study of the dynamics of Gordian Knots. It is good to know who are those who are or can be the most affected in the future by unresolved Gordian Knots, where they are located in geographic and social space, and how they define their identity. The possible losers and victims of the growing Gordian Knot are more important than potential winners who usually belong to a privileged minority.

Both in hierarchical and horizontal systems of interactions, it is important to pay due attention to the identities of elites and differentiated identities of large masses of population that are or could be affected by multiple impacts of the Gordian Knot. The price to be paid is always differentiated and the magnitude of this difference shall be well understood, if we want to contribute to a better understanding of the specific Gordian Knot.

Some special forms of Gordian Knots are Kondratieff's waves and cyclic dynamics of the economic growth and wars, vicious circles of circular

21 B. Goertzel, From Complexity to Creativity, Plenum Press, New York 1997 and also his Chaotic Logic: Language, Thought and Reality from the Perspective of Complex Systems Science, Plenum Press, New York 1994.

22 Very relevant to this part of our study is the well-known textbook by H. Kantz, T. Schreiber, Nonlinear Time Series Analysis, $2^{\text {nd }}$ edition, Cambridge University Press 2003. The paradigm of deterministic chaos and nonlinear dynamics are presented here as useful intellectual tools of modelling and forecasting and chaos control. 
causation in human development ${ }^{23}$, the cases of long lasting backwardness and self-reproducing marginalisation, cases of mis-development, situations of interlocked imbalances and disparities, cases of fast-growing asymmetrical relations in all spaces ranging from military through economic to culture potentials. The long-lasting backwardness or underdevelopment results from vicious circles and/or Gordian Knots.

Liberal democracy as a political structure is better prepared to deal with crises and emergencies than with long-lasting, chronic or inherited problems of long duration. It is one of the functional paradoxes of liberal democracy that it is not efficient in dealing with long-term frames/perspectives.

\section{Time-frames and Gordian Knots}

Gordian Knots are in some respect similar to N. Taleb's Black Swans of Nazism. Fortunately, such a variety of problems is quite rare as Black Swans are rare so rarity makes Knots and Black Swans similar. Another similarity is rooted in the capacity of generating a wide scope of impacts by both Gordian Knots and Black Swans. Yet what is more important is what makes them different - Gordian Knots are not highly improbable. Their probability is relatively high and obviously higher in the present conditions that it was the case few centuries ago due to the increased speed of changes and to their global impact.

In order to be able to make history by innovative strategies, one shall never hide from history. While facing a history of long duration, a much deeper interpretation of events is requested than in any other less sophisticated effort to understand a very recent past. A historian, a sociologist and a strategy maker must think more systematically and deeper in time and wider in space than a reporter or a political commentator of the recent past, for whom something that has happened today should be understood tomorrow.

The linear notion of time is based on the mode of thinking presented above. But this notion is questioned by a faster than ever flow of energy and information. This process of acceleration with uneven speed brings us closer to the reality of globe spanning synchronicity, to a reality of one real time where the past does not matter and future is hardly seen clearly.

If it were actually true, it would be much harder to believe that a remote past really matters and that a history of long duration is of any use in our strategy making. But a sad paradox is that the faster we move into the future, the bigger the significance seems to be of forgotten narratives about the distant past and history of long duration. The remote past takes

23 The vicious circles were very frequently used by Gunnar Myrdal in his explanations of poverty and social inequality. 
a revenge, if it is neglected and forgotten - it still makes an impact even if power centres may not see how powerful the distant past actually is. George Santayana was obviously right when he said that those who did not remember the past were doomed to repeat it. The orientation of psychological recentivism (orientation on the present time alone) is closed for future challenges and leads to a passive mode of ad hoc reactions to immediate risks or already present threats. It presupposes the stagnation of normative and value systems which shape preferences and motivations ${ }^{24}$. It is not conducive to regulatory or innovative strategies and hardly sufficient for adaptive strategies in times of very fast speeds.

Intuitive results achieved by policy makers of a short-term perspective may look pleasant because it is easy to grasp what is close to common sense. Counter-intuitive ideas or theories may look unpleasant because it is disturbing to believe in something that is not in harmony with conventional wisdom. Many innovative strategies are based on counter-intuitive knowledge and visions that go beyond the common sense of short runners.

Let us start from the idea that our systems where we will search for Gordian Knots are intelligent and complex. We will study regions, states, continents and global system as well. An intelligent system has a lot of significant properties that we will take into account.

Such a system:

- can achieve complex goals in complex environments (the capability of strategy-making is highly differentiated),

- can remember experiences,

- can learn from experiences, both successes and failures,

- can be interconnected, interdependent and interactive in relation with its environments ${ }^{25}$,

- can adapt, regulate and innovate in its relations with an environment,

- can self-organise its structure by reintegration of its parts,

- can emerge in accordance with its preferences,

- can forecast the future,

- can move in some spaces,

- can survive crises and disturbances while keeping its integrity,

- can reproduce its distinctiveness and protect its autonomy against some other systems.

24 A. Sepkowski, Wizje i projekty przyszłości a nadzieje zbiorowe [in:] Przyszłość i polityka: Nadzieje i strachy zbiorowe przełomu tysiącleci, E. Ponczek, A. Sepkowski (eds.), Wydawnictwo Adam Marszałek, Toruń 2008, p. 65-86.

25 Here some definitions may help. Interconnectivity takes place when exchange of signals is possible but not always carried out. Interdependence is a situation where the survival and /or identity of systems is based on their mutual interconnectivity regardless of interactions between them. Interactivity is a property of intelligent dynamic systems which are able to act (conflict or cooperation?) while taking into consideration the other systems or/and the spontaneous dynamics of their environments. Communication between the systems is one of the basic forms of their interaction. 
Below is a simple model of relevant variables which contribute to the emergence of a long-lasting problem and which allow us to grasp what kind of data is needed to be able to explain the mechanism of reproduction of the long-lasting problem.

ENDURING FACTORS

Due to the inner nature support and strength

\section{SUSTAINABILITY}

Due to its own efforts and external

\section{LONG-LASTING PROBLEMS TO BE SOLVED}

\author{
LONG-TERM MEMORY \\ Mostly linear causality \\ Looking back to the past
}

\author{
LONG-TERM PERSPECTIVE \\ Mostly non-linear causality \\ Looking forward into the future
}

Time-frame is a notion based on the assumption that there can be a distant past and a distant future or a short-term memory and a short-term perspective of the future combined. These combinations are mindsets in the intelligence of the system. Time-frame as we see it consists of both memories and perspectives, of abilities to look back and to look forward.

The memory of legacies means that the system takes seriously a distant past (for example a history of long duration). If the prospect of the future is viewed in long time periods (such as 15 years plus in strategic planning), one may say that a system is future-oriented. If the memory of the past is too short (forgetting or neglecting the knowledge about the past) and a short-term perspective forecasting prevails, there will be no strategies and ad hoc adjustments and improvisation will be the dominant mode of dealing with uncertainty and risk. For a long time in the pre-modern and even modern part of human history, peoples and their leaders lived in a short time frame and were hardly able to control the developments by strategic thinking and action ${ }^{26}$.

The longer the time frame (both the ability to look back and the ability to look forward), the greater the opportunities for innovative strategies that can create something new that goes beyond the ongoing pressures of spontaneous dynamics of the environment. The long-term memory and perspective into the future is conducive to strategic imagination in policy planning. It helps to keep in mind both the memory of distant legacies and learn from this knowledge and to look into the distant future, forecast, and invent alternative futures in the world of non-linear relations. In a sense, it can allow us to kill Black Swans before they appear on the horizon or to

26 On the long-term statistics and their invisible power of small increases over long periods, compare G. Kołodko, Wędrujący świat, Wydawnictwo Pruszyński, Warszawa 2008. 
prevent them from producing/aggravating the Gordian Knots in human development.

The further we can trace back our experience and the longer our perspective into the future, the more we can limit the unpredictability of accelerating changes. On the other hand, a short time frame increases the risk of uncertain and highly improbable events that would take us by surprise and diminish the efficiency of strategic thinking.

\section{High pace of changes and increasing asymmetry as the most powerful factors}

High speed and the global magnitude of impact are the two most relevant factors that we should take into consideration while searching for a relevant definition of Gordian Knots. On the other hand, it is important not to forget that a Gordian Knot is a set of long-lasting problems, usually inherited from a distant past and somehow (how?) persisting until today. There is a kind of contradiction that is built into the very idea of the Gordian Knot: on the one hand, it is sustained by the legacies of history for a long period of time but on the other hand it is fostered and aggravated by the very fast speed of short-term changes of today. Long duration and high speed are put together to create a dangerous momentum to the Gordian Knots of our time.

The Gordian Knot can be presented as a set of cross-cutting and overlapping causal loops and non-causal interconnections/interdependencies. Gordian Knots tend to be rooted in the causality of both linear and non-linear logic.

In the case of non-linear relations, there is a high dependence on initial conditions, which was discovered by Edward Lorenz in the 1960s (he gave currency to the famous Butterfly Effect phrase). The Butterfly Effect is based on the asymmetry of causes and outcomes: in this case, a small cause (as small as a butterfly) is contributing to the emergence of a huge and eventually dangerous effect. The complexity and network effects in a chaotic process are only one of many ways in which Gordian Knots are created, developed or reproduced. In this perspective, they just occur without being made by anyone in a manner where most important forces are unrevealed, undisclosed and hidden in the foggy and mysterious nature of spontaneous dynamics. On the other hand, the longitudinal aspect of Gordian Knots shows that they emerge from a long way of deterministic causal loops of longue durée. Legacies do not jump on us out of the blue but these old factors shape our culture (and strategic culture, of course) over a very long time with a great deal of linearity in causal determinism. These are quite hard factors, even if they look like millions of drops of water which after 100,000 years break the rock into small pieces. The water is 
soft and a drop of water is very small but a long duration makes it a very strong determining factor with a tremendous potential of destruction and nobody can claim that it is highly improbable event in social space. This geological metaphor helps us to understand the hard power of soft factors which operate over a very long time.

There is the other side of the asymmetry of cause and effect when a big cause produces a very small impact. This asymmetrical causation I would call using an analogy to the Butterfly Effect. I would suggest we can name it a Mountain Effect as we all remember the saying about the mountain which gave birth to a tiny and helpless mouse. The Mountain Effect is at a first glance less troublemaking than its counterpart - the Butterfly Effect. After more careful consideration, however, we feel it is very dangerous when we apply a huge potential and that action brings us very little or negligible outcome. This kind of asymmetric inefficiency can be produced both by nature and by human interactions. What I call here a Mountain Effect is a challenge to strategy makers as it increases the risk of waste and of misuse of all resources. Anything that tends to be or to go out of proportions is a challenge that must be kept under control, if we want to be successful in strategy making.

Dynamic and intelligent systems which can achieve complex goals in complex environments can be divided into four classes. The matrix below is based on two criteria: 1. Low and high speed moving systems, and 2. Shorttime and long-time frame systems. Distinctive properties of intelligent systems can be classified in the following manner:

\begin{tabular}{|c|c|c|}
\hline & High Speed Moving System & Low Speed Moving System \\
\hline Long-term frame & POSTMODERN & MODERN TYPE II \\
\hline Short-term frame & MODERN TYPE I & PREMODERN \\
\hline
\end{tabular}

These two criteria have been unjustly neglected by all scholars of modelling and methodology of intelligent complexity. The addition of this perspective will allow showing that the theory of intelligent systems can be related to different levels of development that is presented here in terms of the modernisation theory.

Gordian Knots can emerge at any stage of human development. They can start growing at a stage of low speed and short-term frame. The late medieval roots of backwardness of some regions are a good example of this. Regions that were late in the industrial revolution or have never experienced such a period of fast increasing productivity tend to lag behind for a long time and have a great difficulty in catching up with the leading regions which were and are the pace-setters for all.

The long duration of certain bundles of problems despite manifold changes around them is a mystery: why do some properties of reality persist when many others disappear? We can wonder what makes some religions 
attractive after many thousand years and many other beliefs evaporate after 50 years or less. We should try to understand how long-duration history or living history is sustained. By doing so we can make our forecasts more deeply rooted in the past and perhaps less fallible in the long run. A better understanding of the distant past is one of the most fundamental sources of successful forecasting of the future and strategy making for a better future.

The distance between pace-setters and laggards can be measured. We may do it quite well yet should still bear in mind that sometimes it is impossible to close gaps that were made 300 years ago and have proved enduring for such a long time. The deeper the roots of disparity or inequality in a timescale, the harder it is to close the gaps and find some equitable solutions.

Asymmetrical reality is fostered and broadened by high speed. Polarisation Effects, fragmentation, disproportions, disparities, diversity, inequality, and differentiation grow faster and become more acute despite the higher transferability of resources and opportunities, higher liquidity of assets as well as higher flexibility in using assets and skills.

Many asymmetries lean to their extremes and may become irreducible. New hierarchies may dominate over technological opportunities to provide for a more horizontal network society based on fair and easy access to many networks. Exclusion of large marginalised groups is hard to alleviate in a world of asymmetries. Asymmetry could be of: threats, identities, power, resources, causes and effects, emotions, cultural legacies of the past, problems to be solved, access to capital and technology, and of anything that matters in strategic thinking. The Gordian Knots are not so painful in all regions of the global system: the less assets and resources are available, the more deeply rooted Gordian Knots can be in the history of long duration. The history of failures and defeats matters more than the history of successes and victories. A society of losers and laggards will suffer more from Gordian Knots than a successful society of smooth progress. The principle of Saint Mathew (to those who have a lot, more will be given) may not allow for a fair redistribution of both public and private goods.

Asymmetry in social relations can be positive, if it allows for doing more with less energy and other resources over a long time. Buckminster Fuller coined the word "ephemeralisation" in order to name such opportunities. He believed that technological advances would result in ever growing prosperity for an ever growing population despite finite natural and human resources ${ }^{27}$.

The synergy effect is another idea about positive asymmetry ${ }^{28}$. It occurs when overall output of the system under study cannot be foreseen by

27 R. Buckminster Fuller, Nine Chains to the Moon, Anchor Books 1938.

28 The development of synergetics as a trans-disciplinary science has been made possible due to intellectual achievements of many scholars, primarily Herman Haken, Buckminster Fuller, Jay Forrester, and Donella Meadows. 
a simple sum of the output of each part of this system. It shows that we can get a surplus of energy or any other final product that goes beyond a simple addition of small energies. The positive asymmetry of synergy refers to the autonomy of the system. The higher the level of autonomy of the system of the dynamics of its parts and environments, the higher the self-organising capacity of the system. A macroscopic order can emerge due to synergy that can reintegrate diverse microscopic forces/positions into an order of priorities relevant for the survival of a larger whole. This particular capacity is based on the ability to achieve a macroscopic order, stability and growth of the system independently of the microscopic interactions of its subsystems. Diversity and tensions of parts are not fully transferred onto the entire system due to its autonomy. A whole is more than the sum of its parts and sometimes it may go out of proportion.

This mechanism allows for synergetic stability and growth as well as synergetic accumulation of power and its efficient use. The multiplication ability really matters in the world of high speed. Positive asymmetry can contribute to at least five important improvements:

1. Macroscopic order - it can be restored independently of microscopic disasters and threats stemming from spontaneous interactions of environments and of the parts of the system.

2. Speed - it can be increased as the system can move faster than it would be allowed by a total energy of its parts.

3. More equal distribution of resources - synergy allows for alleviation of disparities and some disproportions and can lead to a more equitable burden sharing.

4. Predictability - it may increase due to synergy in analytical and forecasting activities of experts and decision makers.

5. Culture of trust and accountability - it can be fostered by synergetic effects of smart cooperation that produces better results and gives more incentives to further cooperation.

The highest level of independence of the system of its own sub-systems, of its environments, of some forms of spontaneous dynamism and of microscopic conflicts between diverse sub-systems we call autonomy. It is never full or unlimited but its proper level is conducive to the selforganisation capacity of the system and synergetic actions against Gordian Knots. In order to be able to perform a bold stroke of the sword as in the Alexandrian Solution, one must be autonomous to a degree that allows for a strategic choice and brave, decisive action. We will revert to a link between autonomy and the Alexandrian Solution in the last section of this paper while discussing the properties of Alexandrian Solutions.

The following model shows some basic components of the Gordian Knot. 


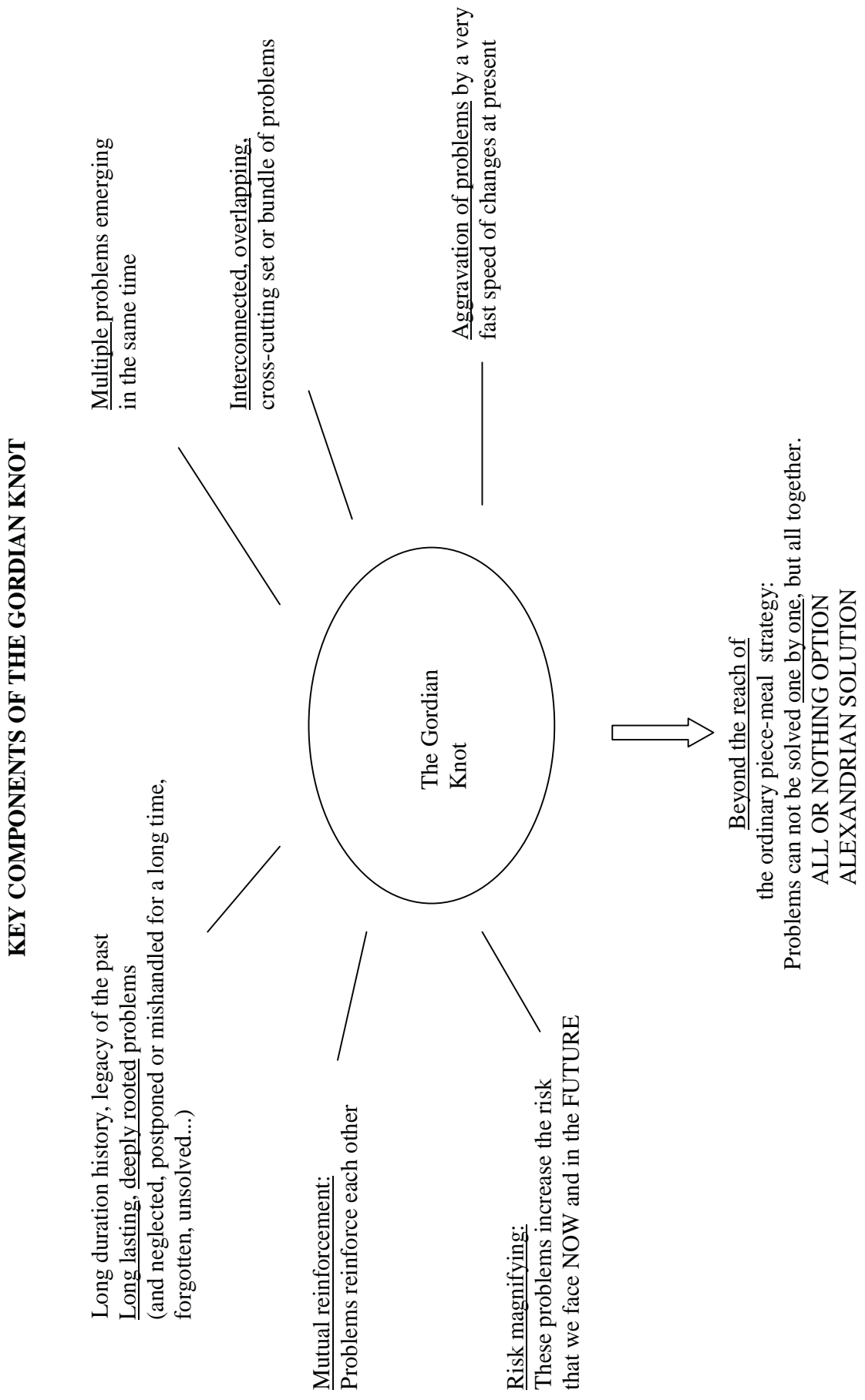


Cyberspace replaces the geometry of three dimensions. Geographical distance matters less than ever due to remote contacts between people who may easy get "in touch" without getting really close, because they can make it from a long distance. The lonely crowd in emotionally empty spaces can be manipulated by the elite of power and knowledge. Plenty of crosscutting spaces without clear boundaries make most people vulnerable to manipulation. And this again may increase the speed of increasing asymmetries in all areas of life. Importantly, many of these asymmetries were born a long time ago and are the legacy of the past which is a stumbling block on the road to a better future. All reformers know how painful it could be when while heading to a brighter future one hits into a hard piece of the past.

Everything can be seen or known in real time with only minor delays. One time reality is a world where global time is more relevant than local times and where short-time spans dominate over long-term perspectives. In many areas, we can be approaching the absolute speed - the speed of light - by absolute velocity of electronic data on the information superhighways of the Internet and multimedia. Short-term profitability, faster pace of capital accumulation and commoditisation of everything are fundamental features of capitalist market economy. And it facilitates the emergence of one time reality and the destruction of long-term frames that seem to be indispensable to strategic thinking. The more we feel confined to the present one real time, the more we should try to keep a long-term frame, and to look critically back at the distant past and a distant future. The widening of our time frames is the only way out of the trap of living in one-time reality.

Weak signals matter more than strong ones due to the higher pace of changes but are harder to observe and grasp. That is why many of those Weak Signals can be overlooked. The risk of undesirable surprises and exceptional events is higher in many spaces where we live. We are taken by surprise quite frequently in spite of the fast flow of information and better knowledge. This context makes our systems more vulnerable to Gordian Knots.

Challenges to cognition. In the reality of asymmetry, there is higher risk of fundamental loss of orientation by human beings. New cognitive disturbances foster a higher risk of misperception and wrong judgment. Symbols without meanings and foggy meanings make it harder to create a meaningful global culture with distinctive common values.

\section{Alexandrian solutions: distinctiveness of the bold cut}

Gordian Knots cannot be solved by a step-by-step approach due to their nature and that of complex intelligent systems and spontaneous dynamics 
of their environments. Distinctive properties of the Alexandrian Solution seem to be the following:

1. As a cut of the sword, it must be radical enough to be able to destroy the long-lasting and self-reproducing essence of the Gordian Knot. Radicalism does not mean a revolutionary action in most cases. However, this solution must be going deep and reaching the hidden roots or underpinning causes of the long-lasting cluster of problems. The minimal level of radicalism is the ability of the power centre to cut through the fundamental links (at least) that keep a bundle of problems together ${ }^{29}$. In a sense, the Gordian Knot must be uprooted by one stroke of a sharp sword. The first cut must be the deepest and use as much strength (intellectual rather than physical!) as possible. It is a test of the sharpness of the strategic sword that we use.

2. It should be comprehensive enough. That means it must take seriously into consideration how old as well as complicated and intertwined a specific Gordian Knot is. Before cutting, one should know how much power one must apply and how wide a cut should be to succeed. The harder the case of the Gordian Knot, the more power and determination would be needed to cut or dismantle it. Comprehensive solutions are broad in scope and deep in reaching the causes.

3. It should be based on a relatively high level of the autonomy - from the spontaneity of its environments - of the strategy making centre and the system that it commands. High dependence of the strategy maker upon the spontaneous dynamism of the environment can be an obstacle in designing and implementing the strategy that is both radical and comprehensive.

4. The sword must be well focused on the most critical parts of the Gordian Knot and its roots. The Alexandrian strategy presupposes smart prioritising of fields where the first bold stroke should be applied. Focusing is equivalent to being sharp and fast enough in getting your thing done. My karate coach told me once - be elegant in fighting, if you have to fight do your utmost to make your enemy impotent with one single and precise stroke of your well-trained hand, do not drag him and catch him many times without a proper effect.

5. It should be based on proper timing - the Alexandrian solution must be done not too early and not too late, just right in time. To be most successful, it should be applied at the right time. It is important to re-

29 The story about three sons of a dying father and his test of strength of his sons is a good example of an Alexandrian solution that can be applied without cutting anything in physical terms. Only the youngest son dissolved/dismantled a bundle of thin pieces of wood that were bound together into something hard beyond human power. The other older, and probably physically stronger, sons could not break it without a clever step of dismantling it first. Another good example is Columbus' egg that he put straight on the table in a very simple manner but first he started to think out of the box. 
member that good timing as regards the strategy is security and sustainability is as vital as time which is money in business.

6. It should be oriented toward positive synergy and to the possibility of appearance of some Virtuous Circles in human development. Synergy and self-organisation capability is a crucial precondition of positive asymmetry and by using this we can achieve effects that are bigger than the forces we have got to use.

7. It should be designed in a smart way to be efficient in the long run; it should be good for a much longer time than tomorrow alone.

8. It should consider global public goods and common needs of the whole mankind such as indicated in the Oath of Alexander the Great. Nowadays, it is crucial to take into account peace, human security, inclusiveness, non-discrimination, enhancement of creativity and free$\mathrm{dom}^{30}$. Values first. The goals of the Alexandrian strategy should follow the values and not the other way around. Parochial or/and particular interests rarely provide good guidance to the Alexandrian strategy of problem solving.

9. The general approach that seems to be the most conducive to the Alexandrian strategy is concerned optimism, a strong belief that human rationality and compassion matter a great deal and if put together can make a difference. The biggest mistakes are made not by fools but by wise people who underestimated their power to change the world for the better. Evil survives not due to the actions of bad people but due to inaction of the good ones. A concerned optimist believes that one should be good and get done as much as possible.

In order to plan for an Alexandrian strategy in any area of activity, it is good to find the weakest part of the Gordian Knot and hit at it at the beginning. The distinction below shows how we can proceed in search of a weak link of the target, of a particular well defined Gordian Knot.

I. Weak event...............weak signal.... weak link of the target

II. Strong event. trong signal .weak link of the target

Accumulated knowledge about the two tracks shown above. Power/ property relationship is an institutional framework where we can find the weakest link and perhaps the most relevant to the solution we need. The biggest methodological question is how we can know ex ante what variety of Alexandrian Solution is available. Can we know it only ex post, after an

30 In his oath in the city of Opis in Mesopotamia in 324 B.C., Alexander the Great referred to "prosperity in peace" and equal treatment of the Greeks and barbarians. "For me, every virtuous foreigner is a Greek". In his idea of the "contract of love", all peoples should "live like one people in harmony and for mutual advancement" and they "must not consider god to be an autocratic despot but a common father of all". The philosopher Eratosthenis, the director of the library in Alexandria heard these words from Alexander's comrades who were ear witnesses to them. 
effort to get rid of the Gordian Knot or can we really find out it before we do anything?

Some intellectual devices can be of relevance for a more successful search for an Alexandrian Solution. The following recommendations are heuristics that can foster creative thinking and strategic imagination.

- Think out of the box - do whatever you can to break from the dominant mode of thinking, from common sense and conventional wisdom, go beyond any established ideology and religion, go beyond strategic conventions of your time by constructing images, spectacles and narratives that prefigure new ways of seeing and living... For example, in a comparative study of Triple Mezzogiorno we can think in the box and out of the box as well. The following in-the-box factors or indicators frequently used in regional studies of backwardness and underdevelopment can be found: a strong tradition of the village and a high percentage of peasants in the population of the region, very late industrialisation and urbanisation, attitudes of conservatism driven by strong religious beliefs, culture of mistrust, low disposable income and high poverty, acute social inequalities, and lack of natural resources. Out of the box explanations of backwardness or blocked modernisation can refer to the distant past, legacies the geographic location of the region at the state border, etc.

- Search for counter-intuitive ideas and learn from whoever is able to deliver this variety of inspiration. The source of inspiration is irrelevant. What really matters is what you will do with this inspiration and where you go from the here and now.

- Learn as much as you can from all crises because a short-term crisis may help develop a strategy for long-term solutions as it was the case with the New Deal policy of Franklin Delano Roosevelt in the 1930s.

- Remember that there is no obsolete knowledge. Only non-trivial knowledge that goes beyond banality of narrow minded experts is of greatest value. Cooperation of highly specialised experts with generalists is more conducive to the Alexandrian strategy than a simple addition of specialists in their distinctive fields. Good communication and trust between specialists and generalists is the best combination that may allow all of them to participate in well-organised learning and problem solving. ${ }^{31}$ Narrow specialists alone can hardly produce a synergy as they tend to think within the boxes of their distinctive fields of specialised knowledge because they know almost everything about very limited areas. The generalist knows a lot about the methodology of strategy making and problem solving and has some knowledge

31 In their famous book, Warren Bennis and Burt Nanus distinguished four strategies of leadership: 1. attention through vision, 2. meaning through communication, 3. trust through positioning, 4. the deployment of self; Leaders: Strategies for Taking Charge, $2^{\text {nd }}$ ed., Collins Business 2007, passim. 
about special fields of interest as well. The generalist can help invent something out of the box of specialised knowledge and this can be tested by specialists. A proper mix of specialists and generalists in a strategy making team is a strategic problem per se. If you need an Alexandrian strategy, you must be able to construct decision making teams in an Alexandrian way. In our times, the king is and must be replaced by a team of strategy makers because our world is more complicated and more complex than the world of Alexander the Great.

- Dream about alternative futures and do not be afraid of thinking the unthinkable. Have the courage of hope that we achieve what we want if we are guided by brave and visionary leaders who share global responsibility and are ready to go beyond parochialism and the narrow-minded local perspective. Responsibility for the future begins in dreams.

- Question all traditions and many well established institutions as they may preserve stumbling blocks to your innovations. Alienate yourself from alienations in which you were put by old orders in many areas of life.

- Widen the scope of the possible by sharing your ideas with others who might be willing to help you in searching for an Alexandrian strategy. Coalitions of those who might help in finding it shall not be based on ignoring legitimate concerns and knowledge of other partners in strategy making. Listen carefully to possible and actual opponents in order to be able to predict the power of resistance to the Alexandrian strategy you are to design and implement.

- Define your Gordian Knots as clear and sharp as possible and in order to do it, use all sources of wisdom, knowledge and information well. Remember about long-duration history and do not be afraid of the quick flow of the present time. Look from the perspective of future scenarios at the present time and look far back for underpinning causes of the Gordian Knot. Time and timing matter much more in a society of fast speed and cross-cutting vectors of changes. The faster the time flow, the faster a strategy maker must be at the right time in the right place. The speed of information flow is very high due to computers and innovations in this field but human capacity to process and use the information are not getting any faster. Humans are not fast enough. Their minds act as bottlenecks in the process of strategy making. This information overload results in either delays in making decisions or our making of wrong decisions. So instead of providing solutions to Georgian Knots we may produce even tougher knots for future generations. We should warn ourselves against this kind of risk everyday as it is possible that something important has been discovered yesterday that we do not know and it can have a tremendous impact upon the problems we are trying to solve. 
Bounded rationality models seem to be more relevant and adequate in searching for an Alexandrian strategy than all pure models of rational choice. If we want to maximise benefits and minimise costs or to achieve our goals with the best means that we may have, we should assume that it all happens in a framework of cultural and institutional boundaries that must distort human capability of reasoning. In psychological terms, the field of bounded rationality is limited by interference of many historyrelated and culture-bound factors, such as:

- knowledge about the Gordian Knot and the situation in which one has to act,

- emotions of strategy makers and other relevant social groups (hopes, fears, etc.),

- intentions and motivations,

- norms and values accepted by reference groups,

- common sense and intuitive knowledge,

- interests: public and private, local and global, class, national, regional, corporate, etc.

It is wiser to assume that all actors are bound by their models of rationality than to believe that there are universal and pure models of pragmatic or economic rationality. Rationalities are constructed by people and strongly coloured by history and culture in which people construct their notions of rational behaviour.

\section{Conclusion}

Tsunami Effects are more feasible due to a magnitude and frequency of wicked problems, but super wicked problems and - first of all - Gordian Knots are by far the most wicked component in civilisations of our times. The art of strategy-making, however, may help in our search for the least clumsy solutions. In any case, "it takes an optimist to be an optimist nowadays", as the outstanding American comedian Groucho Marx said during the crisis of the 1930s. Tsunami Effects are around us even if we are unaware of their existence. Let us hope that the humankind shall not fall victim to our strategic incapacity.

\section{Bibliography}

Bennis W., Nanus B., Leaders: Strategies for Taking Charge, $2^{\text {nd }}$ ed., Collins Business 2007.

Buckminster Fuller R., Nine Chains to the Moon, Anchor Books 1938.

Conklin J., Wicked Problems \& Social Complexity [in:] Dialogue Mapping: Building Shared Understanding of Wicked Problems, Wiley, New York 2005.

Conklin J., Dialogue mapping: building shared understanding of wicked problems, Chichester, England: Wiley Publishing 2006. 
Dillon M., Global security in the 21 $1^{\text {st }}$ Century [in:] The Globalization of Security, Briefing Paper, Chatham House, October 2005.

Goertzel B., Chaotic Logic: Language, Thought and Reality from the Perspective of Complex Systems Science, Plenum Press, New York 1994.

Goertzel B., From Complexity to Creativity, Plenum Press, New York 1997.

Grint K., The Leadership Challenge of Wicked Problems, Warwick Business School, Warwick University, Slides for Henry Stewart Talks.

Kantz H., Schreiber T., Nonlinear Time Series Analysis, $2^{\text {nd }}$ edition, Cambridge University Press 2003.

Kołodko G., Wędrujący świat, Wydawnictwo Pruszyński, Warszawa 2008.

Lamentowicz W., Reformizm szwedzki, PWN, Warszawa 1977.

Lamentowicz W., Państwo współczesne, wyd. 2, Wydawnictwa Szkolne i Pedagogiczne, Warszawa 1996.

Lamentowicz W., Strategia państwa: teoria państwa aktywnego wobec zmian spontanicznych, Elipsa, Warszawa 2015.

Leary T., Potter B.A., Evolutionary Agents, Ronin Publishing 2004.

Levin K., Cashore B., Bernstein S., Auld G., Overcoming the tragedy of super wicked problems: constraining our future selves to ameliorate global climate change, "Policy Sciences", Vol. 45 (2), 23 May 2012.

Rethinking Geopolitics, G.O. Tuathail, S. Dalby (eds.), London 1998.

Rittel H.W.J., Webber M.M., Dilemmas in a general theory of planning, "Policy Sciences" 1973, No. 4.

Sepkowski A., Wizje i projekty przyszłości a nadzieje zbiorowe [in:] Przyszłość i polityka: Nadzieje i strachy zbiorowe przełomu tysiącleci, E. Ponczek, A. Sepkowski (eds.), Wydawnictwo Adam Marszałek, Toruń 2008.

Taleb N.N., Fooled by Randomness: The Hidden Role of Chance in Life and in the Markets, Penguin Books, London 2004.

Taleb N.N., The Black Swan: The Impact of the Highly Improbable, Penguin Books, London 2007.

Virillio P., Prędkość i polityka, Wydawnictwo Sic!, Warszawa 2008.

Abstract

My purpose is to explain why it is so frequent that policy makers both public and private fail in their efforts to solve problems. The main question is why educated and experienced persons cannot achieve their goals by reasonable decisions and actions. Among many causes and reasons (spontaneous changes of postmodern societies, limits to rationality of decision makers), I shall focus on two types of problems - wicked problems and Gordian Knots. The very characteristics of these types of problems are conducive to Tsunami Effect, to complete incapability of designing strategies which are efficient enough. Gordian knot is defined here as a wicked problem having some specific features and causes. Notions of Tsunami Effect and Gordian Knot are regarded as an innovative contribution to the general theory of strategy and the theory of decision making.

Keywords: problem solving, hard cases in strategy making, wicked problems, Gordian Knots 
Złośliwe problemy i węzły gordyjskie: zwiększone ryzyko efektu wystąpienia efektu tsunami w nowoczesnym rządzeniu

Streszczenie

Celem artykułu jest wyjaśnienie, dlaczego publiczne i prywatne osoby lub podmioty tworzące politykę tak często odnoszą niepowodzenia w swych wysiłkach zmierzających do rozwiązania problemów. Główne pytanie brzmi: dlaczego wykształcone i doświadczone osoby nie są w stanie osiągnąć celów drogą rozsądnych decyzji i działań? Spośród wielu przyczyn i powodów (spontaniczne zmiany ponowoczesnych społeczeństw, ograniczona racjonalność decydentów) wybrano do analizy dwa typy problemów problemy złośliwe oraz węzły gordyjskie. Już same ich własności sprzyjają efektowi tsunami, całkowitej niezdolności projektowania wystarczająco wydajnych strategii. Węzeł gordyjski definiuje się tu jako złośliwy problem posiadający pewne konkretne cechy i przyczyny. Pojęcia „efekt tsunami” i „węzeł gordyjski” uznaje się za nowatorski wkład w ogólną teorię strategii oraz teorii podejmowania decyzji.

Słowa kluczowe: rozwiązywanie problemów, trudne przypadki określania strategii, złośliwe problemy, węzły gordyjskie 